\title{
Da applicabilidade da fallencia aos não commerciantes
}

De todas as refórmas commerciaes a que mais tem preoccupado a attenção dos legisladores e jurisconsultos, é, incontestavelmente, a que se refere ao instituto juridico da fallencia.

Por isso é que, com razão, diz Lehr (I): os trabalhos, sobre essa materia, feitos na França, Belgica, Italia, Allemanha, Inglaterra e nas duas Americas, nestes ultimos 20 annos, encherião uma bibliotheca.

Escolhendo nós, portanto, a questão da applicabilidade da fallencia aos não commerciantes, para objecto deste artigo, obedecemos, tão sómente, á importancia do assumpto, que, na verdade, constitue hoje uma das preoccupações mais dignas de nota por parte dos commercialistas modernos.

Estudando a fallencia, sob o ponto de vista historico, verifica-se que, em sua origem, ella se applicava a todos os devedores.

(I) Code de Commerce Portugais-Introduction. 
E' bem conhecido o rigôr da Lei dos I2 Taboas, sobre a execução dos devedores, em geral, rigôr que, posteriormente, foi modificado devido á grita dos plebeus e a intervençăo dos pretores, que suavizando as severidades da lei civil, derão-lhe um cunho juridico differente, sem comtudo modifical-a quanto á sua applicação aos commerciantes e não commerciantes, cuja distincção continuou a não conhecer.

A Ordenança de 1673 , que, incontestavelmente, constitue o inicio da codificação commercial franceza, influenciada pelas opiniões dos jurisconsultos italianos da média edade, estabeleceu que, á fallencia, ficarião sujeitos todos os devedores que não pagassem as suas dividas (I).

Em I 807, porém, com a promulgação do Codigo Commercial Francez, que no dizer de Vidari, é o pai de todos codigos do commercio, a fallencia deixou de ser um meio de liquidação de todos os devedores, para se tornar um processo de execução applicavel tão sómente aos commerciantes.

Não obstante, porém, a disposição do Codigo, a jurisprudencia franceza, nos primeiros annos, vacillou sobre a applicação dos principios referentes á fallencia aos devedores communs, como assegurão Lion Caen et Renault (I)

A lei franceza de 28 de Maio de 1838 , que revogou o Liv. $3 .^{\circ}$ Codigo Commercial, sobre a fallencia, em nada alterou a sua natureza, estabelecendo modificações apenas na parte penal, cujo rigôr marcial, denunciava o caracter de Napoleão, impresso nesse mesmo Liv. de Codigo.

(I) Lyon Caen et Renoult--Droit. Com. vol, 7.0 n. 9, Jousse-Traité de la Justice criminelle-Liv. 3.0 tit. 5.0 parte $4{ }^{\text {a }}$ Des banqueroutes.

(I) Op. cit. 
D'ahi a uniformidade de todos os Codigos, modelados pelo Francez, em considerar a fallencia um instituto applicavel só aos commerciantes.

E o Codigo Brasileiro de 1850 , copiado dos Codigos Hespanhol e Portuguez, modelados pelo Francez, não podia deixar de reproduzir a doutrina de suas fontes, sobre a natureza da fallencia, declarando, como fez no art. 797 que todo o commerciante que cessa seus pagamentos, considera-se fallido ou quebrado, disposição essa traduzida litteralmente do art. 437 da citada lei franceza de 1838 .

A corrente de opiniões, porém, manifestada, já nos corpos legislativos, já nos trabalhos doutrinarios, nestes ultimos annos, é toda favoravel em tornar a fallencia um meio de liquidação applicavel a todos os devedores em geral.

$\mathrm{Na}$ propria França, berço do systema restrictivo da fallencia ao campo commercial, já se tem agitado a yuestão da applicabilidade desse instituto aos devedores communs, tendo sido apresentados dois projectos nesse sentido, sendo um em 1879 e outro em i 881 , que não lograrão seus propugnadores vêr convertidos em lei ( $\mathrm{I}$ )

$\mathrm{Na}$ Camara italiana, quando se discutio o novo Codigo do Commercio, a mesma questão foi objecto de grande discussão, como nos attestão Castagnola, Bolafio e Gianzona (2).

A tendencia da legislação portugueza é para nivelar os devedores civis aos commerciantes, sujeitando

(I) Ad. Thaller-Des fallites en Droit comparé-vol. I. ${ }^{\circ}$

(2) Nuovo Codice italiano-Turim-1886. 
uns e outros ao mesmo regimen de execução, como bem se percebe da exposição de motivos do Codigo Commercial de i 888 .

Estudando as legislações extrangeiras, vê-se que ellas se dividem em 3 systemas diversos - sobre a applicação da fallencia.

O primeiro-circumscreve esse instituto juridico ao campo exclusivamente commercial. A este systema pertencem as legislações-franceza, belga, italiana, e, em geral, as de todos os paizes da America dọ Sul.

O segundo-submette á fallencia todos os devedores insolvaveis, quer commerciantes, quer não commerciantes. Seguem este systema as legislações-ingleza e allemã.

O terceiro - finalmente, que podemos chamar mixto, considerando a fallencia applicavel a todos os devedores insolvaveis, todavia estabelece algumas differenças de processo, e de sancção penal, sendo esta mais rigorosa para os commerciantes. Perfilhão este systema, entre outras, as legislações austriaca, hungara e noruegueza.

A legislação suissa, adoptando um systema de transacção, permitte a inscripção no registro do commercio a todos os devedores civis, ficando estes só por esse modo, sujeitos ás regras da fallencia (I).

O legislador brazileiro de $\mathrm{i} 890$, no afan de reformar a legislação do regimen politico anterior, expedio o Decr. n. 9 I 7 de 24 de Outubro d'aquelle anno, o qual revogou por inteiro o Titulo $3 .^{\circ}$ do Cod. Commercial, que se intitula das quebras.

(1) Lei federal suissa de II de Abril de 1889, art. 39. 
Deixando de parte os defeitos de methodo e de doutrina de que se resente esse Decreto, defeitos esses oriundos do açodamento com que foi feito, para só tratarmos delle na parte referente ao assumpto deste artigo, verifica-se desde logo, que o legislador republicano perfilhou o systema restrictivo da fallencia ao cornmercio, declarando que:

o commerciante sob firma individual, ou social, que sem relevante razão de direito, deixa de pagar no vencimento qualquer obrigação mercantil liquida e certa, entende-se fallido ( $\mathrm{I}$ ).

E completando o seu pensamento contido nessa disposição, declarou mais o legislador no art. I40-que os devedores por titulo civil, no caso de cessaçãa de pagamentos ou de insolvencia, reputar-se-hão insolvaveis, mas não fallidos.

Só estão, portanto, sujeitos á fallencia, segundo o Dec. 917 de 24 de Outubro de I890, os commerciantes.

O mesmo legislador republicano de i 890 no Dec. i69 A de ig de Janeiro, que expedio, approximou-se da melhor doutrina, estabelecendo no art. 20 , que os devedores por effeitos commerciaes, comprehendendo os que contrahissem emprestimos hypothecarios e penhores agricolas, ficavam sujeitos á jurisdicção commercial e á fallencia.

Mas tendo o Dec. 9i 7 de 24 de Outubro do mesmo anno de 1890 , declarado no art. I..$^{\circ}$ que os commerciantes é que estão sujeitos á fallencia, estabelecendo excepção especificada com relação aos correctores, agentes de leilöes, trapicheiros e commissarios de

(1) Dec. 917 de 24 de Outubro de $1890-$ art. $10^{\circ}$ 
transporte no art. I39, havendo mais estabelecido no art. 140 que os devedores por titulo civil, não estão sujeitos á fallencia, é claro que o referido art. 20 do Dec. 169 A foi revogado pelos arts. I. ${ }^{\circ}$ e I4O do Dec. 9 I 7 citado, na parte referente á fallencia.

Não nos parece, portanto, acceitavel a opinião de alguns advogadios, entre os quaes, o illustre Dr. João Motta (I) que entendem ser o art. 20 do Dec. I69 A, uma excepção ao art. I. do Dec. 9 I 7.

Não nos consta que, mesmo na vigencia do art. 20 do cit. Dec. I69 A, fosse elle applicado, sendo aberta a fallencia em devedores civis por effeitos commerciaes e por emprestimos hypothecarios e agricolas.

Mas, andou bem o legislador bra\%ileiro, adoptando o systema restrictivo da fallencia aos commerciantes, com todas as suas consequencias?

Antes de apresentarmos a nossa opinião, vejamos os fundamentos desse systema.

Procuram legitimal-o seus propugnadores, allegando que, a natureza e multiplicidade das operações commerciaes, o credito que ellas exigem, os riscos aos quaes se expoem, constituem a razão da lei sobre as fallencias, ao mesmo tempo favoravel e rigorosa ao devedor (2).

D’ahi concluem elles que, si ir fallencia constitue uma necessidade manifesta no commercio, porque ella assegura de um modo positivo os credores auzentes e presentes, evitando que uns se locupletem com a ignorancia dos que não conhecem a situação embaraçosa do devedor, lançando-se sobre seus bens, em detrimento dos outros, essas vantagens não apparecem nas rela-

(I) Processo das Fallencias-- 1898 .

(2) Lyon Caen et Renault op. cit. vol. $7 .^{\circ}$ n. 37. 
ções civis, onde o individuo não tem necessidade de ultrapassar os seus recursos, nem de se entregar aos azares da especulação (I).

Sem embargo desses motivos e da opinião dos jurisconsultos que sustentam o systema restrictivo da fallencia, adoptado pelo nosso legislador, pensamos que elle não é o melhor, nem representa o periodo superior da evolução moral e juridica dos paizes, que o seguem, como brilhantemente sustenta o illustre professor da Universidade de Bolonha (2).

Antes de tudo. A differença que os adeptos desse systema procuram enxergar entre commerciantes e não commerciantes, é arbitraria, por isso que a classe dos primeiros, como é sabido, não está ainda bem definida na linguagem juridica.

A qualidade de commerciante, é determinada pela pratica de actos do commercio por profissão habitual.

Mas, que são actos do commercio? Um problema ainda insoluvel para a doutrina, um tormento para $o$ legislador, um enigma para a jurisprudencia (r).

E é, justamente, pela impossibilidade de se caracterizar os actos mercantís, differençando-os clos outros actos da vida commum que Lyon Caen et Renoult (2) dizem não encontrar para elles uma definição nas condições absolutas do direito e da justiça.

A profissão habitual sendo uma questão de facto, é por isso mesmo sujeita á apreciação dos juizes e tribunaes, aos quaes é dado um largo poder para decidir, si os actos mercantis, praticados por um indi-

(I) Ad. Thaller-op. cit. vol. I.o

(2) Cesare Vivante-Diritto Commerciale.

(I) Dr. Brasilio Machado-Da unificação do Direito Privado-1897.

(2) Op. cit. vol. I. ${ }^{\circ}$ n. 102. 
viduo são tão numerosos, que attestem exercicio habitual do commercio.

Mas, como um individuo póde praticar actos do commercio por profissão habitual, e não ser commerciante, como os prepostos, a doutrina e alguns codigos, como o de Wutemberg, exigem, além dos dois elementos apontados, que os actos commerciaes sejam feitos em proprio nome, para que a pessoa possa ser considerada commerciante.

Dest'arte o commerciante é aquelle que pratica actos do commercio por profissão habitual e em seu proprio nome. fallencia.

E só estes, portanto, estão sujeitos ao regimen da

Entretanto, encontram-se nas legislações, que perfilham o systema restrictivo, individuos que, não reunindo as condições de commerciante, como os correctores, agentes de leilões e trapicheiros, estão todavia sujeitos á fallencia ( $\mathrm{I}$ ).

Não ha, portanto, quer na doutrina, quer na jurisprudencia, um criterio seguro para se distinguir os commerciantes das outras classes sociaes.

Para o systema restrictivo, não é só a qualidade de commerciante, por parte do devedor, que autoriza a declaração da fallencia. E' preciso que a divida ou obrigação não satisfeita, seja tambem commercial.

Pela nossa legislação, essa exigencia é expressa no artigo $1 .^{\circ}$ do Dec. 917 de $1890 . \mathrm{E}$ no $\S 2 .^{\circ}$ do mesmo artigo $\mathrm{I} .^{\circ}$ o legislador expressamente declara:

(I) Dec. 917 cit., art. 139. 
que ás dividas civis podem concorrer com obrigaçoes mercantis para constituir o estado de fallencia, mas só por si, não autorisam a declaração della.

Este artigo resolveu a questão muito debatida, em os nossos tribunaes, ao tempo da vigencia do Titulo $3 .^{\circ}$ do Cod. Commercial sobre quebras, qual a de saber se a cessação de pagamentos de dividas civis dava ou não logar á fallencia, em vista da disposição generica do art. 797 do mesmo Codigo.

Mas, se esse segundo requesitn,-falta de cumprimento de obrigações commerciaes, é que determina a fallencia, os defensores do systema que analysamos, deveriam, para ser coherentes, amplial-a aos não commerciantes, que faltassem ao cumprimento destas obrigaçôes resultantes de actos do commercio ( $\mathrm{I}$ ).

Esta verdade, tão bem comprehendeu o nosso legislador do Dec. I69 A de i 9 de Janeiro de 1890 , que no artigo 20 , deixou claro não haver obstaculo no caracter civil do devedor, para o effeito de sujeital-o á fallencia, quando se trata de falta de cumprimento de obrigações commerçiaes.

Infelizmente, conforme já se fez notar, o legislador do Dec. 9i 7 do mesmo anno de 1890 , revogou o art. 20 citado, com verdadeiro sacrificio de logica.

Não vemos razão para se distinguir as obrigações commerciaes das civis para os effeitos da fallencia.

E na verdade; si não padece duvida que o commercio repousa sobre o credito, e si é certo que este é indivisivel, o não pagamento das dividas civis, que, incontestavelmente se reflecte nas relações commerciaes, denunciando um estado precario do devedor, deve, por isso mesmo, autorizar a sua fallencia.

(I) Vidari-Corso de Diritto Com. vol. 8. $765^{2}$. 
Além disso, é injusto, que o credor civil, que soffre todas as consequencias da fallencia, não tenha direito de requerer a sua decretação.

Entre as proprias legislações que seguem o systema restrictivo, alguns admittem a fallencia por falta de pagamento de dividas civis.

E' assim que, o Codigo Commercial belga (lei de I 8 de Abril de I85I), declara no art. 487, que a falta de pagamento de dividas civis, póde dar logar á abertura da fallencia, desde que se ache abalado o credito commercial do devedor.

O novo Codigo hespanhol, segundo Romero y Giron, não exigindo, expressamente, como fazia o Codigo de 1829 , que a fallencia fosse determinada pela falta de cumprimento de obrigações mercantis, tem permittido que a jurisprudencia firme, que a falta de pagamento de dividas civis, dá logar á sua declaração.

A jurisprudencia franceza, segundo attestão Ruben de Couder e outros jurisconsultos, por muito tempo vacillou si, diante do texto da lei de 1838 , que não declara, expressamente, que só a falta de pagamento de dividas commerciaes, é que dá logar á fallencia, teve por muito tempo sérias hesitações, sobre se as dividas civis tambem determinavam essa situação.

T) exposto se conclue que, os dois elementos exigidos pelo systema restrictivo, para determinar a fallencia, não encontram no systema geral do direito, bazes solidas, sendo certo até, que, com relação ao segundo elemento, falta de cumprimento de obrigações commerciaes, as legislações são discordantes. 
Analysando os argumentos com que os defensores do systema restrictivo, procuram justifical-o, deprehende-se logo, que elles não conseguem demonstrar a inutilidade da applicação da fallencia aos não commerciantes.

E' facto notado nestes ultimos tempos, que a especulação tem avassalado todas as classes sociaes; e tão amplas e multiplas se tem tornado as relações da vida civil, que bem se póde assegurar a sua confusão com as relações commerciaes.

As grandes transacções lucrativas sobre immoveis, são a prova cabal da semelhança das relações civis ás commerciaes.

E é, justamente, attendendo a isso, que alguns Codigos, como o italiano e rumano, já declararam commerciaes, as transacções feitas sobre essa especie de bens, para o effeito de sujeital-as á competencia commercial.

Pelo crescente desenvolvimento do espirito de associação, modernamente, vê.se surgir em toda parte grandes sociedades de natureza civil, entregando-se á operações tão importantes e arriscadas, como as operações commerciaes.

Entretando os seus credores, dignos de interesse, como os de um commerciante, não são protegidos pelas regras da fallencia (I).

A nossa legislação sobre sociedades, melhorou de algum modo, estabelecendo a liquidação judicial, para as sociedades anonymas, que o seu objecto seja civil, que commercial (2).

(1) Lyon Caen et Renault op. cit. vol. $70^{\circ}$ n. 37.

(2) Decretos-30 de Dezembro de 1882 e de 4 de Julho de I891. 
A legislação suissa, que estabelece a fallencia, a toda pessôa individual, ou collectiva, desde que esteja escripta no registro, não hesitou em considerar as proprias sociedades, que tem fins moraes e intellectuaes, sujeitos a este meio de liquidação, uma vez que, pelo mesmo registro, adquiram a personalidade juridica (I).

Os tribunaes de algumas cidades importantes de França, como Lyon, têm se afastado da lei escripta, estabelecendo um regimen de liquidação collectiva, calcado sobre as regras da fallencia, contra os devedores civis insolvaveis (2).

Este facto, como bem diz o citado escriptor Thaller, só póde significar, a necessidade de uma refórma energicamente reclamada pelas transformações economicas do seculo.

E na verdade, si a insolvabilidade do devedor civil e a fallencia do commerciante, são dois phenomenos economicos da mesma natureza, por isso que, ambos denunciam perturbações e embaraços da fortuna privada, creando uma situação grave para seus credores, não ha razão para a dualidade do processo da execução, maxime, com manifesta desegualdade de garantias para os credores do devedor civil, como estabelecem as legislações que seguem o systema restrictivo de fallencia ao commercio.

O commerciante que cessa seus pagamentos, ou como estabelece a nossa legislação, deixa de pagar só uma pequena divida liquida e certa, sem comtudo, estar insolvavel, é logo submettido aos rigores de um processo especial de liquidação, onde ao lado da pro-

(I) Brustlein-commentario ao art. 30 da lei de 18 de Abril de 1889.

(2) Ad. Thaller-op. cit. 
tecção aos credores, apparece a ordem publica, reclamando a sua punição como criminoso.

Entretanto, o devedor civil, que não tem necessidade de ultrapassar os limites de seus recursos, nem de se entregar aos azares da especulação, como dizem os defensores do systema referido, pelo abuzo do credito ou por simulação, tornam-se insolvaveis, dando enormes prejuizos a seus credores, muitas vezes numerosos, offendendo assim, á moral e á ordem publica e não estão sujeitos ao mesmo processo especial de liquidação dos commerciantes!

O legislador brazileiro, considerando a insolvencia uma situação criminosa, declarou no art. 337 do Codigo Penal: que o devedor não commerciante que se constitue em insolvencia, occultando maliciosamente seus bens, ou simulando dividas, em fraude de seus credores, será punido com a pena de prizão cellular de 6 mezes a 2 annos.

Ora, si os mais directamente prejudicados com a insolvencia malicioza e fraudulenta do devedor civil, são os credores, a estes a lei, devia, logicamente armar de meios efficazes para a liquidação do devedor, como o processo collectivo de fallencia.

Accresce que as garantias que a nossa legislação concede aos credores contra o devedor civil insolvavel, são deficientes e póde-se mesmo dizer imprestaveis.

A acção pauliana ou revogatoria, pela sua natureza e pela prova que exige do dólo, quer do devedor, quer do possuidor de bens, não constitue, é claro, uma garantia sufficiente aos credores contra os devedores astuciosos.

Além disso, as despezas enormes, que uma acção dessas acarreta, são outros tantos motivos, para que os 
credores, na maioria dos casos, desistam de seus direitos, deixando em paz, o seu devedor.

E é á sombra dessas difficuldades, creadas pela lei, que presenciamos todos os dias a fingida ruina de individuos pouco escrupulosos, que simulando uma insolvabilidade, para obter accordos amigaveis de seus credores, com grandes rebates, d'ahi a pouco surgem na sociedade, gozando os resultados da sua fraude.

De resto, as limitações impostas pela lei nas execuções, contra o devedor civil, constitue, entre nós, enorme embaraço, na descoberta dos bens deste, maxime attendendo ao grande desenvolvimento de propriedade mobiliaria.

Não temos um regimen de liquidação contra os devedores civis.

As leis existentes, não garantem de um modo efficaz os credores contra a insolvencia de taes devedores, como acabamos de vêr.

Urge, portanto, que o legislador brazileiro, que entendeu reprimir essa situação de devedor fraudulento, sujeitando-o á sancção penal, organize, para ser coherente, um processo collectivo de liquidação, em vantagem dos credores, divorciando-se desse modo, do máu systema que perfilhou.

Si receios tiver o legislador em adoptar o systema inglez e allemão, que se approxime ao menos de melhor doutrina, como fizeram as legislações da Austria, Hungria e Suissa.

Dr. Sabriel de Rezende. 